\title{
ERRATUM
}

\section{Erratum to: The Clinical Effectiveness of Ranibizumab Treat and Extend Regimen in nAMD: Systematic Review and Network Meta-Analysis}

Andriy Danyliv (1) Julie Glanville $\cdot$ Rachael McCool $\cdot$ Alberto Ferreira

Adrian Skelly $\cdot$ Ruth Pulikottil Jacob

Published online: April 17, 2017

(c) The Author(s) 2017. This article is an open access publication

Erratum to: Adv Ther (2017) 34:611-619

DOI 10.1007/s12325-017-0484-0

The authors of this manuscript have noticed two mistakes since publication:

1. In the Methods section of the paper (under "Search strategy") it reads "The search strategy for MEDLINE is shown in Supplemental Fig. 1 (Fig. S1) and the other searches are available on request."

It should read

"The search strategy for MEDLINE is shown in Supplemental Fig. 1 (Fig. S1) and the other searches are also available in the supplementary material from page 28 onwards."

The online version of the original article can be found under doi:10.1007/s12325-017-0484-0.

A. Danyliv $(\bowtie)$

Novartis Ireland Limited, Dublin, Ireland

e-mail: andrii.danyliv@novartis.com

J. Glanville · R. McCool

York Health Economics Consortium, University of

York, York, UK

A. Ferreira · A. Skelly

Novartis Pharma AG, Basel, Switzerland

R. P. Jacob

Novartis Pharmaceuticals UK Limited, Surrey, UK
2. In the supplementary material in Table $\mathrm{S} 2$, in the Medline row the number ' 2845 ' should be '6845'.

Open Access. This article is distributed under the terms of the Creative Commons Attribution-NonCommercial 4.0 International License (http://creativecommons.org/licenses/ by-nc/4.0/), which permits any noncommercial use, distribution, and reproduction in any medium, provided you give appropriate credit to the original author(s) and the source, provide a link to the Creative Commons license, and indicate if changes were made. 